\title{
Black ASL: The Effects of its Discovery on the Community
}

Carolyn McCaskill, Ph.D.

Deaf Studies Conference

November 2, 2018 


\section{Black ASL Authors}

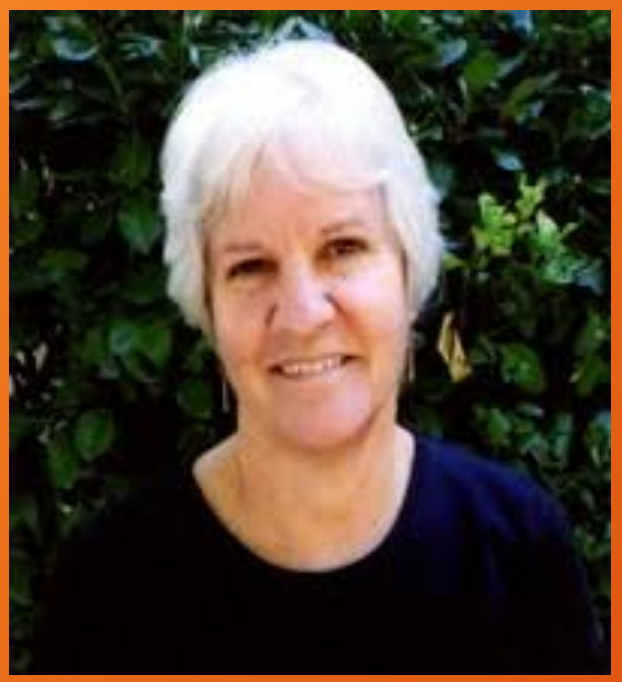

Dr. Ceil Lucas

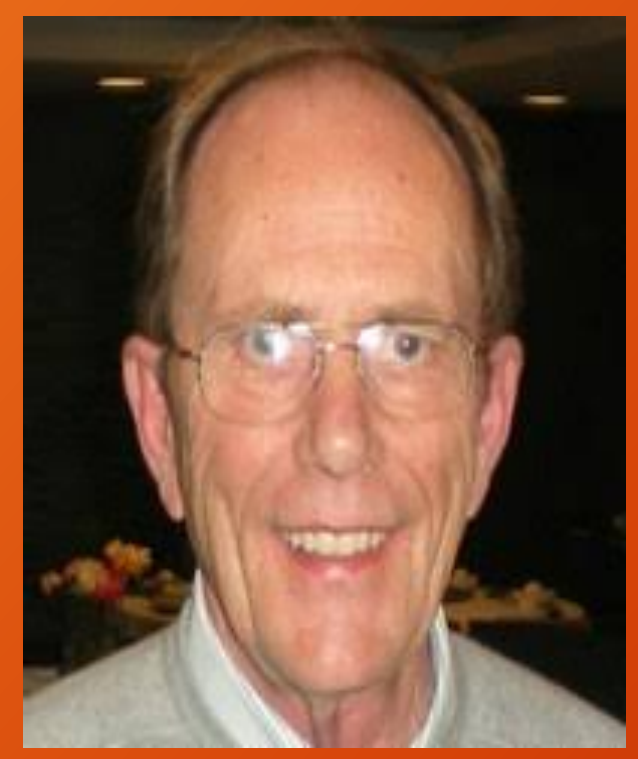

Dr. Robert Bayley

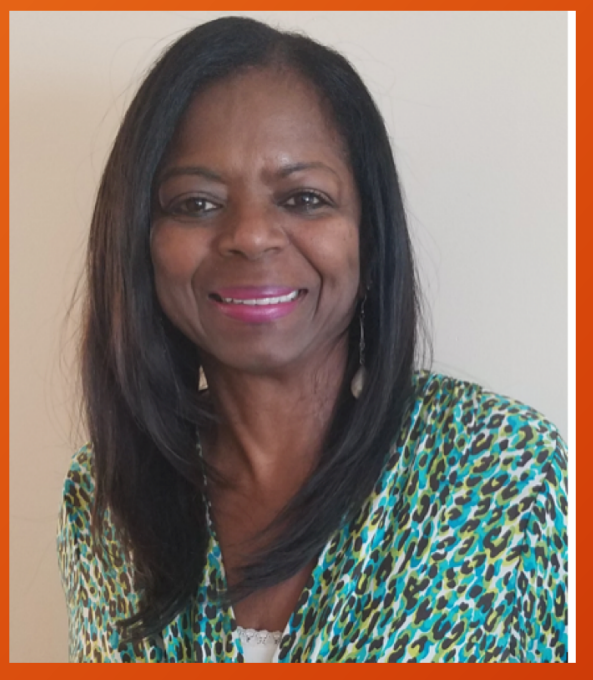

Dr. Carolyn McCaskill

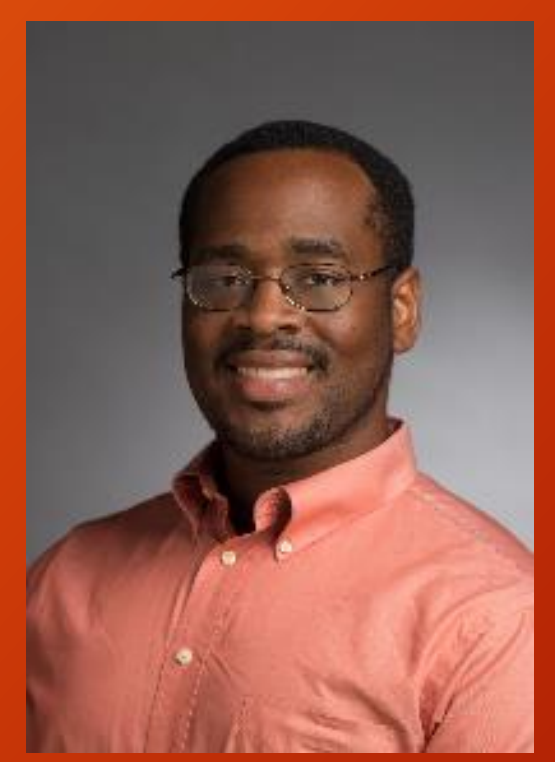

Dr. Joseph Hill

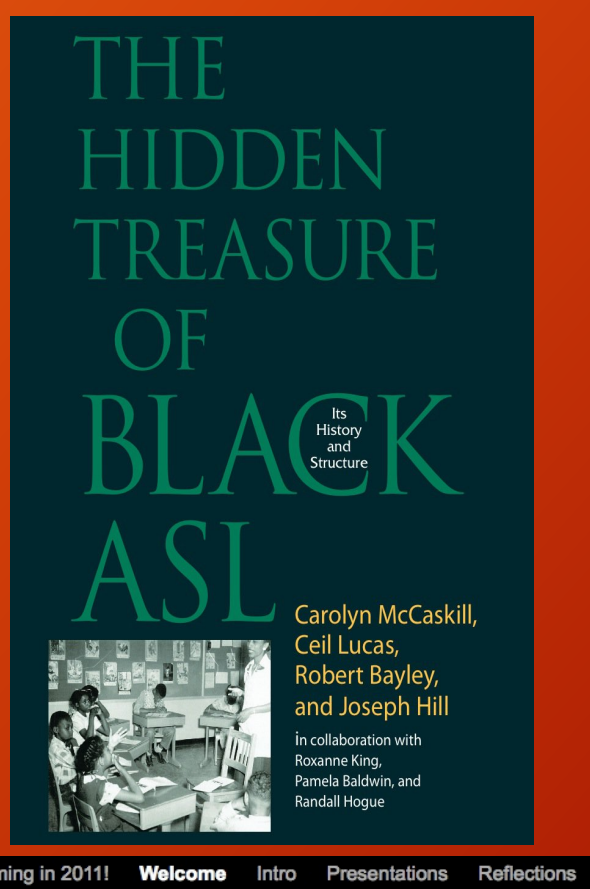

The Black ASL Project

Text and DVD COMING SOON! Click HERE to see the book's cover!

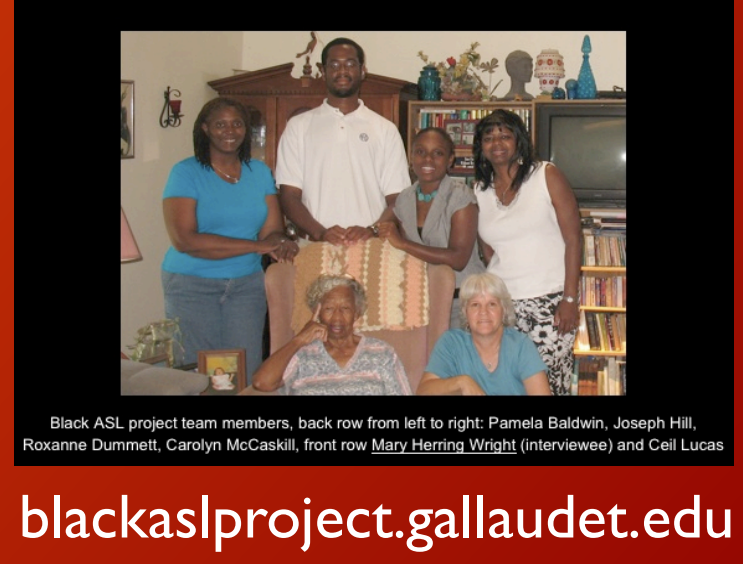

2 


\section{The Black ASL Project at a Glance 2007 - 2013}

Sites visited in order of the year in which schools for Black Deaf children were founded:

1. Raleigh, North Carolina (1869)

2. Houston, Texas (1887)

3. Little Rock Arkansas (1887)

4. Talladega, Alabama (1892)

5. Hampton, Virginia (1909)

6. New Orleans, Louisiana (1938)

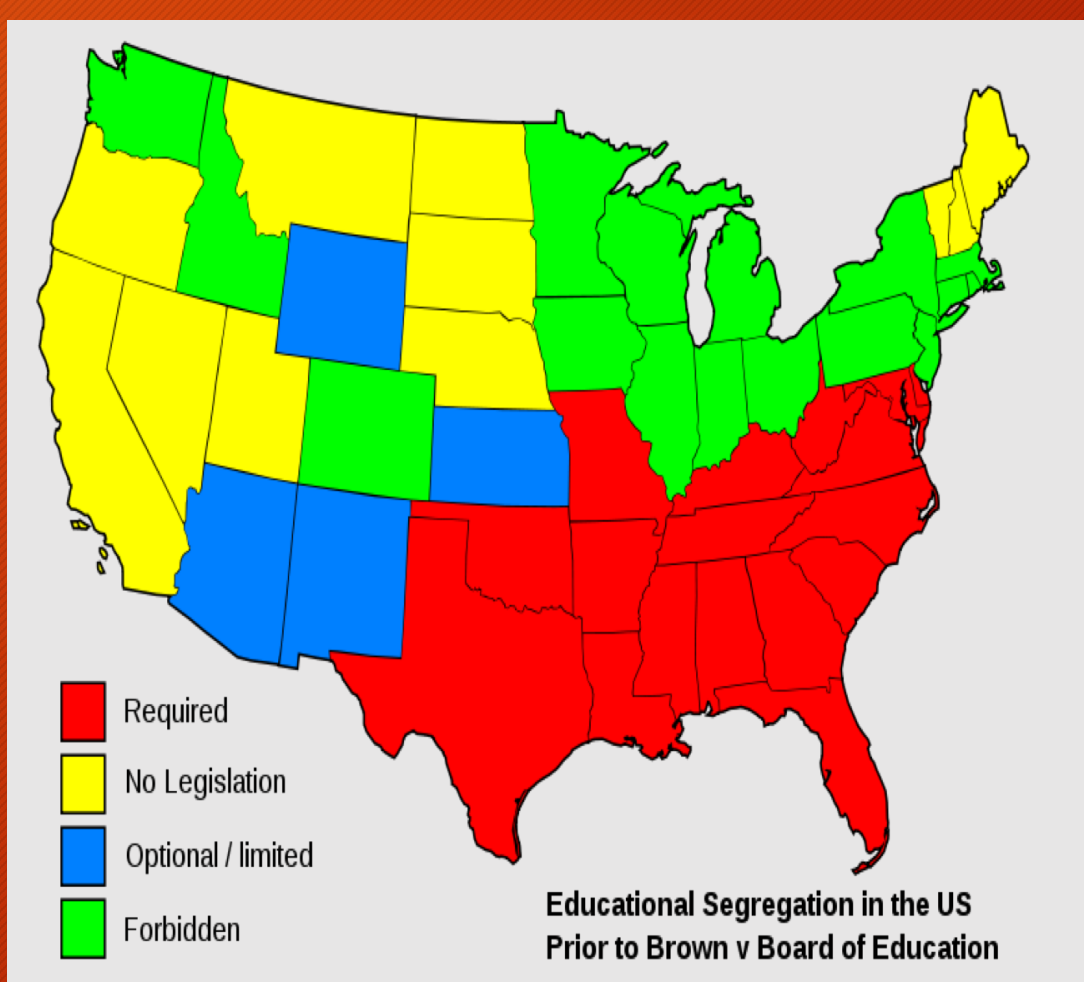




\section{The Black ASL Project at a Glance}

Under 35 - Virginia

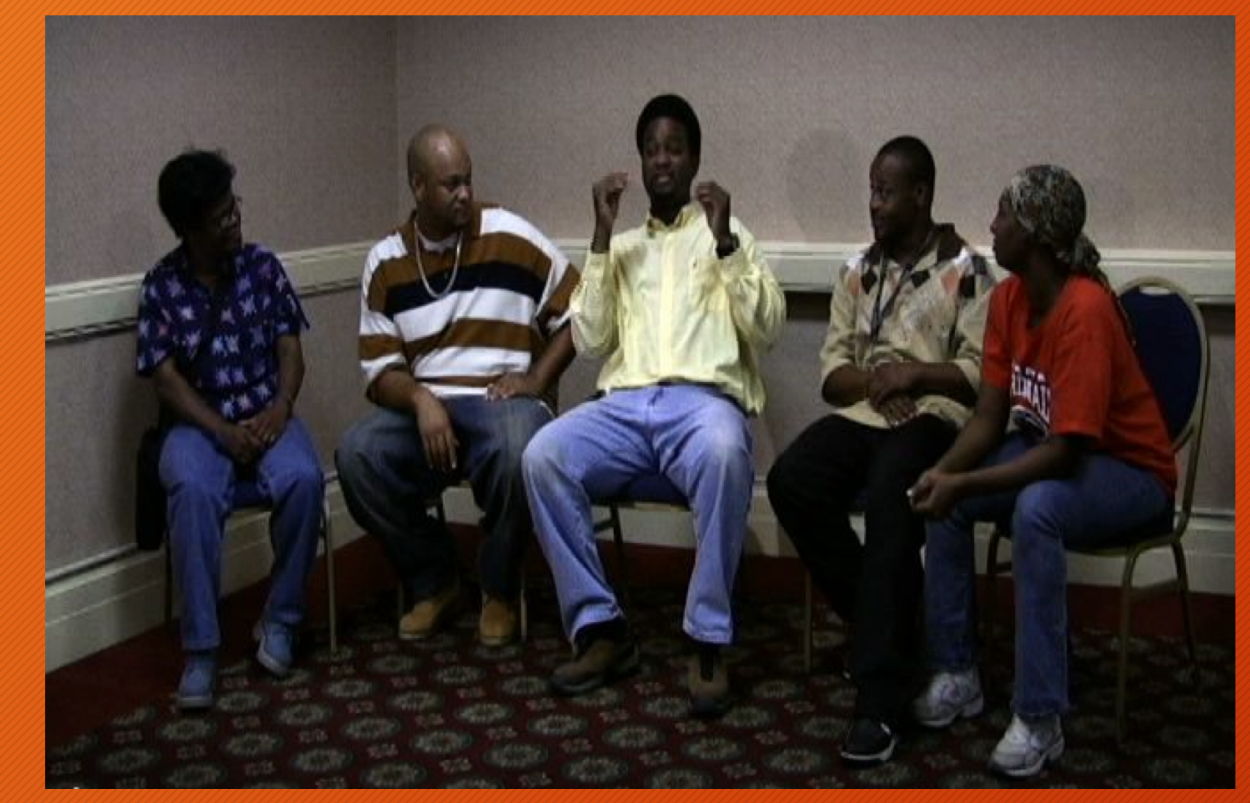

Signers at each site were grouped according to age:

- "Over 55" - attended school during segregation $(\mathrm{N}=64)$

- "Under 35" ( $\mathrm{N}=32)$

\section{Over 55 - North Carolina}

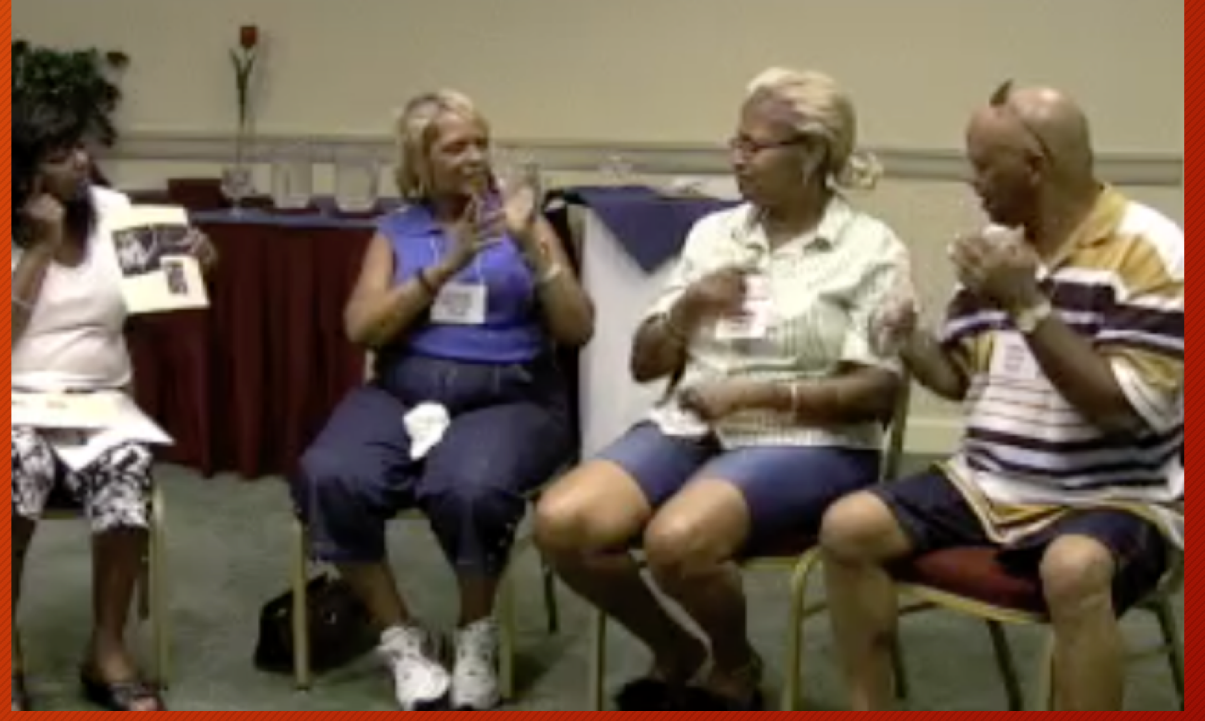

Filming occurred during the following:

- Free conversation

- Structured interviews focusing on language use and school history. 


\section{Black ASL Mosaic}

2-handed vs. Forehead Size of 1 -handed location vs signing space signs lowered

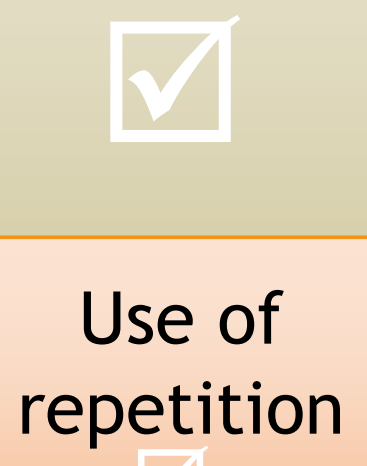

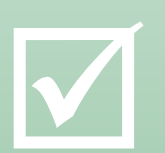

Use of role shifting

Mixed Results
Amount of mouthing

Mixed Results
Incorporation of $A A E$ into signing

Vocabulary differences 


\section{PERCEPTION}

- In the Black ASL study, we provide an overview of our findings about participants' attitudes towards their own variety.

- Our results suggest that some Black signers have negative attitudes towards their traditional variety despite the fact that, in a number of respects, Black ASL is closer to the standard taught in ASL classes and found in ASL dictionaries.

- Results also show a very positive attitude towards Black culture, as manifested in part in the incorporation of African American English lexical items into Black ASL, particularly by younger Black signers. 
A Clip of Black ASL 


\section{Language Perceptions of Black ASL}

"Under -35" Group

"White ASL is more advanced"

"Black use a lot of space; White use little"

"More facial expression, more powerful in Black ASL"

"Different style in Black ASL"

"Attitude in Black ASL"

"White signers with sealed lips; Black signers mouth"

"White signers are more snobby"

"Ebonics-influenced ASL"
"Over 55" Groups

"Whites were more advanced and better"

"More news and vocabulary in White"

"More education"

"White is faster; black is slower like turtle"

"Made fun of my signs so I changed to white ASL" 


\section{A Powerful Deaf School History}

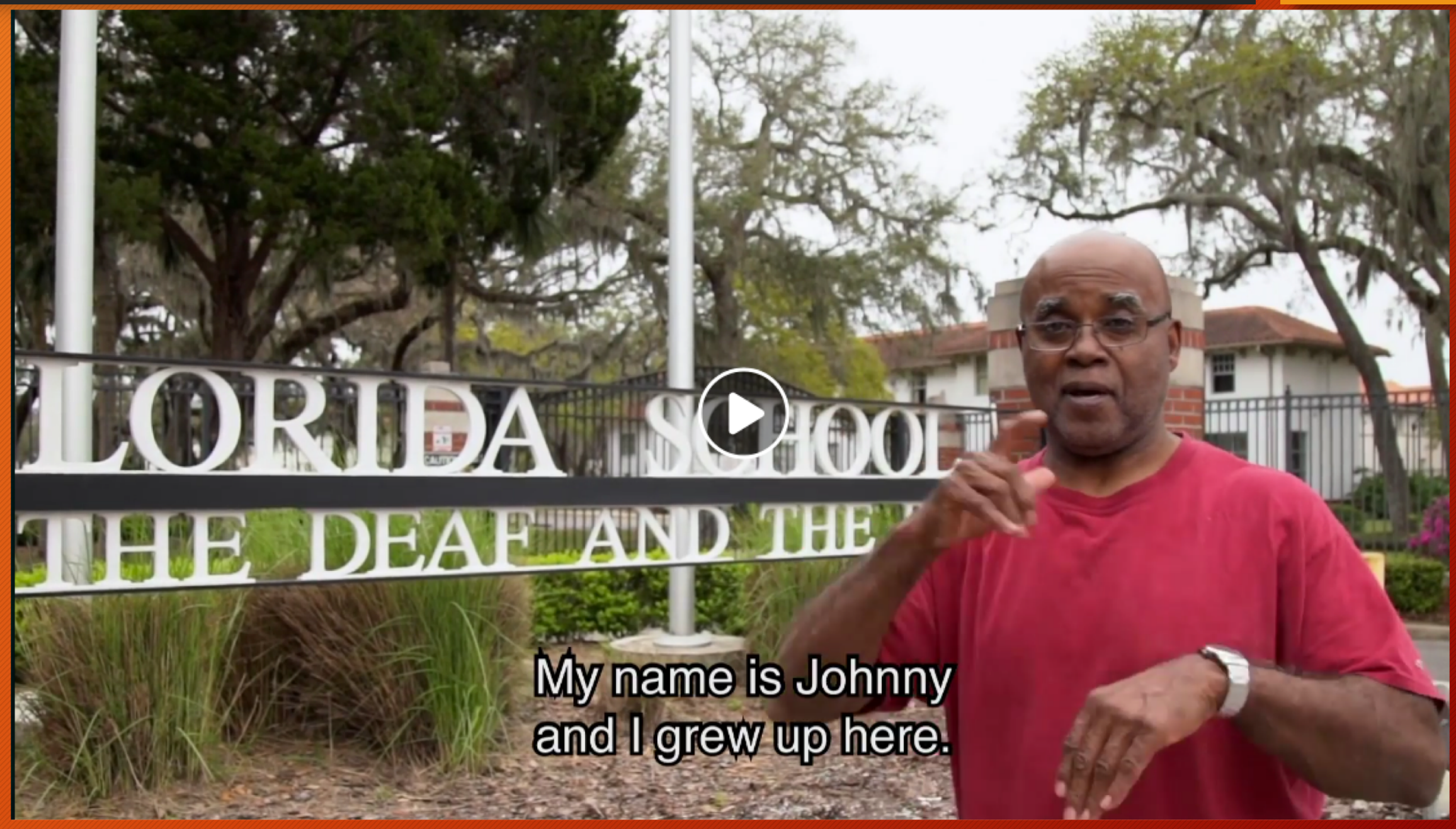


KENTUCKY SCHOOL FOR THE DEAF HONORS BLACK STUDENTS Lexington Herald Leader
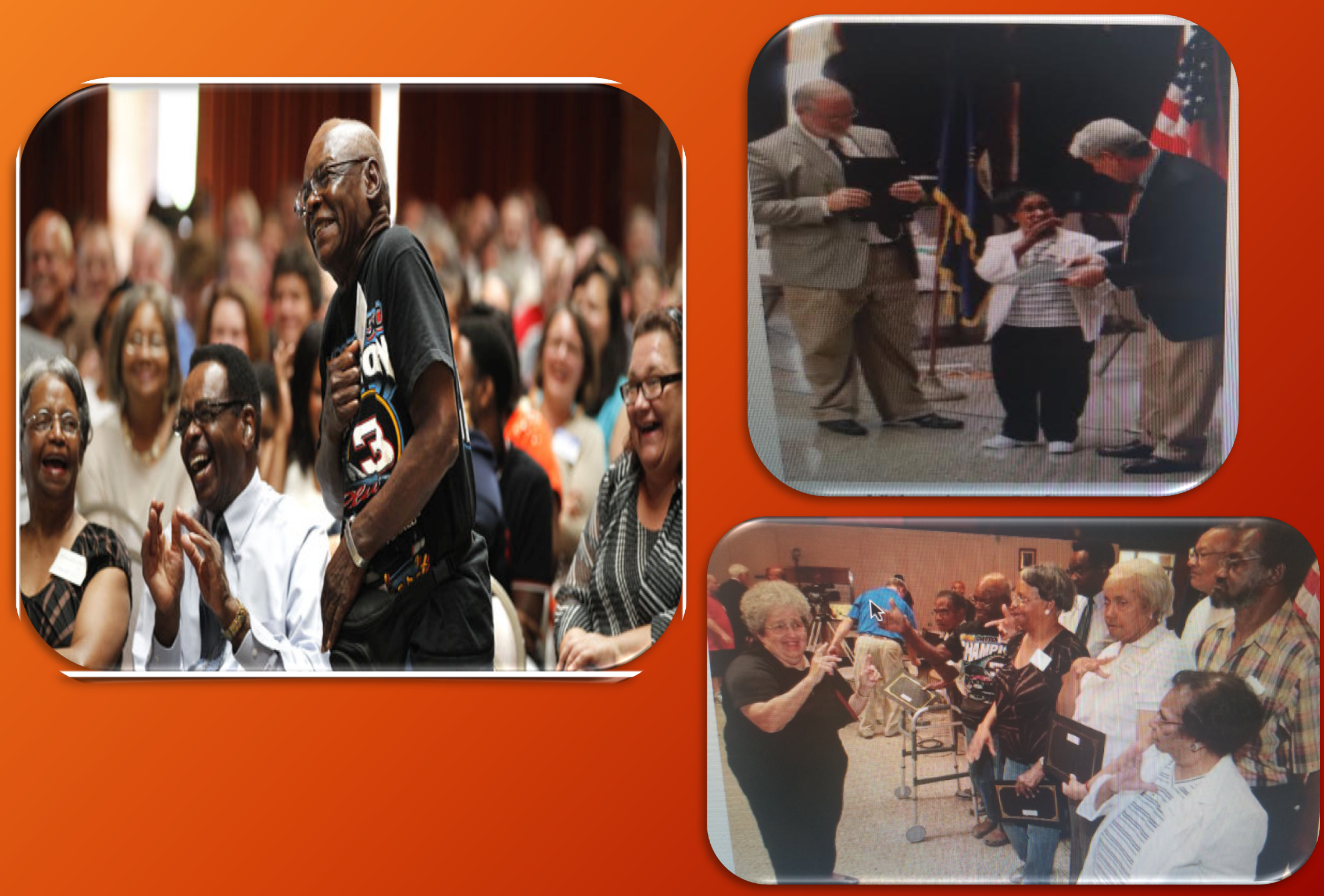


\section{Black Deaf History}

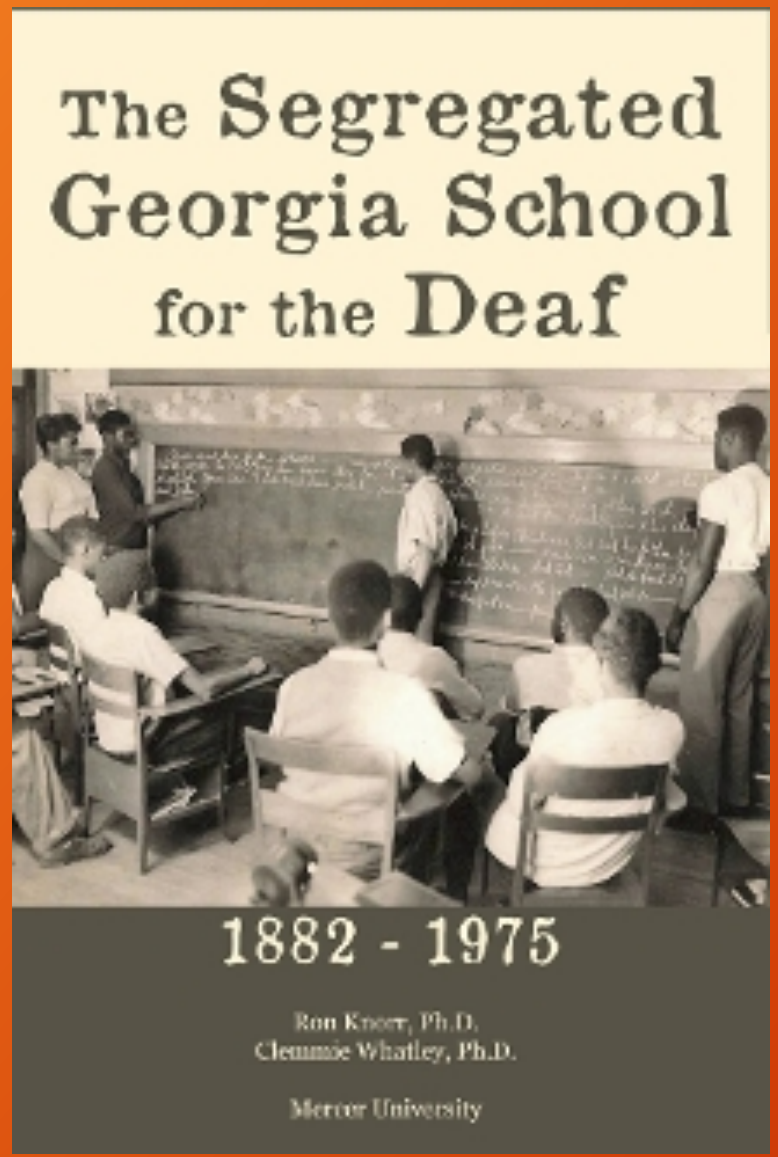

Ron Knorr and Clemmie Whatley (2018)
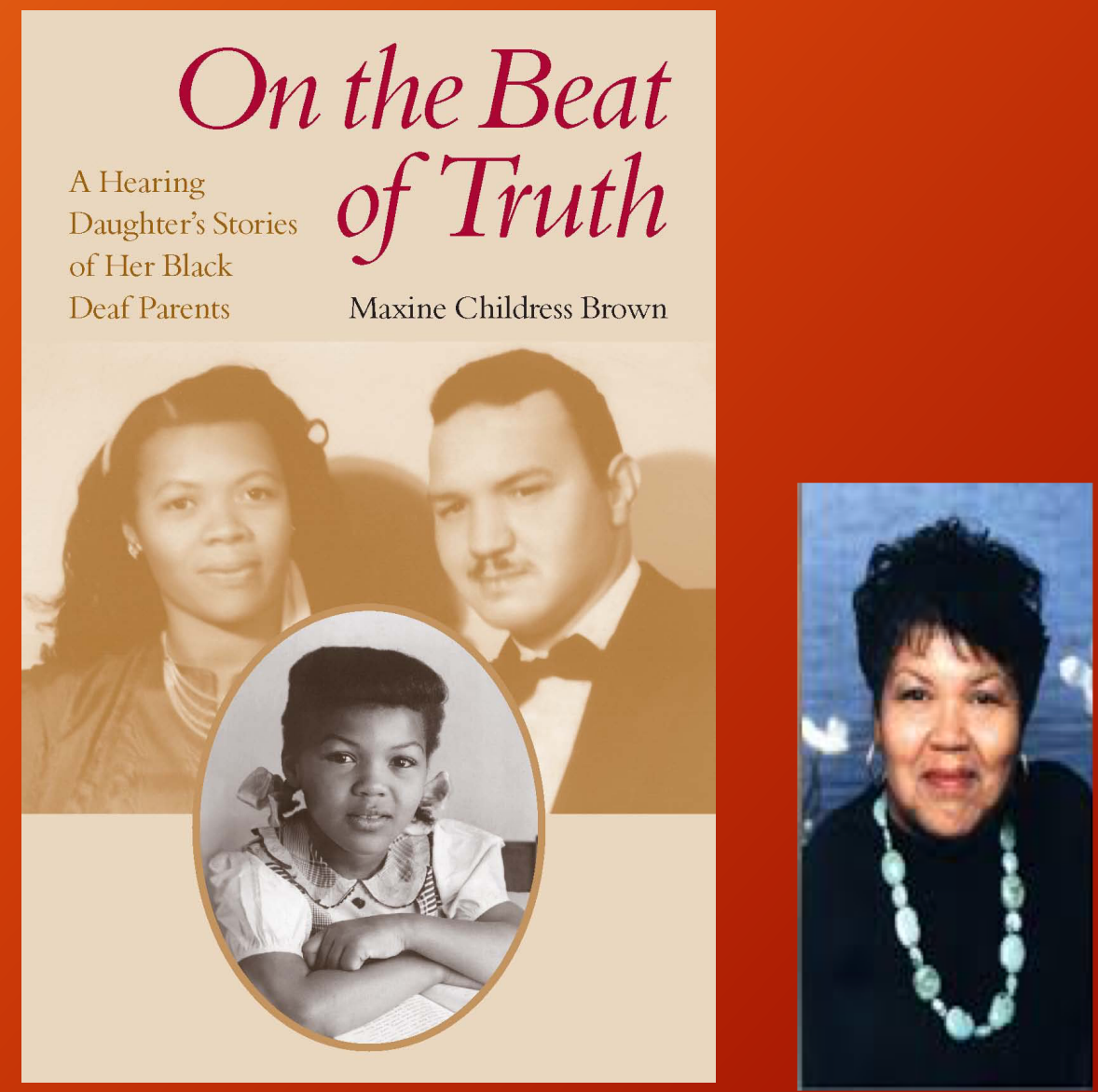

Maxine Childress Brown (2013) 


\section{Published Articles}

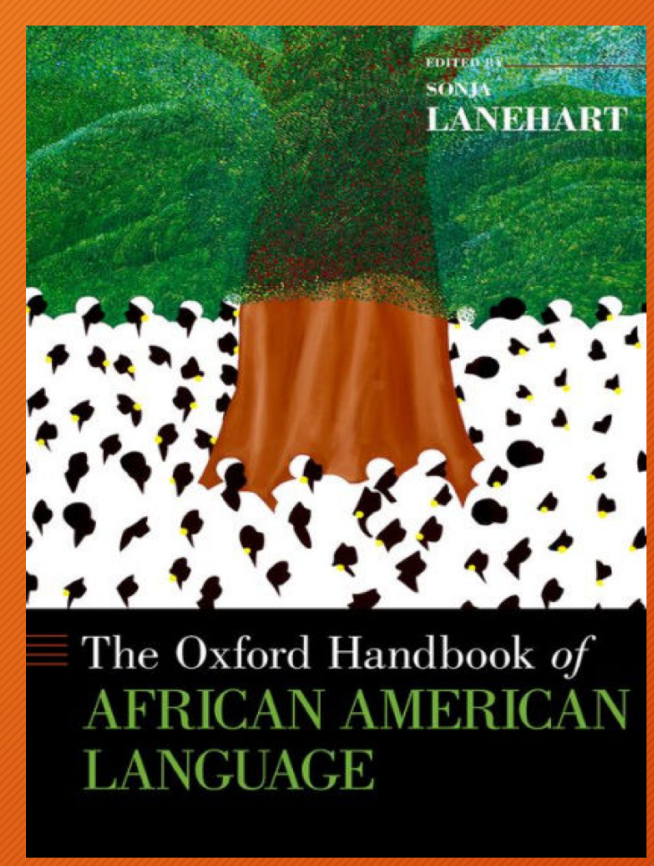

\section{(2015)}

Contributors:

Joseph Hill

Carolyn McCaskill

Robert Bayley

Ceil Lucas
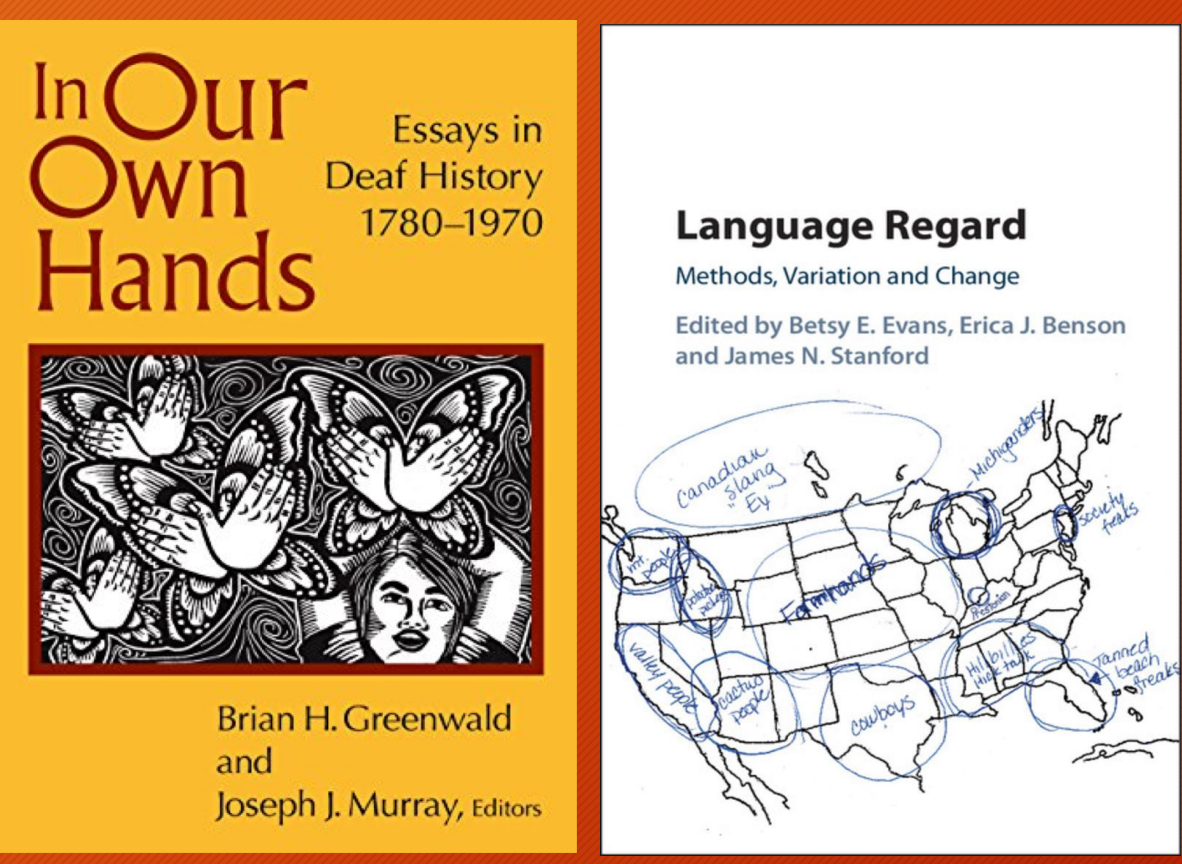

(2016)

Contributors:

Carolyn McCaskill

Ceil Lucas

Robert Bayley

Joseph Hill
(2018)

Contributors: Robert Bayley Joseph Hill Ceil Lucas Carolyn McCaskill

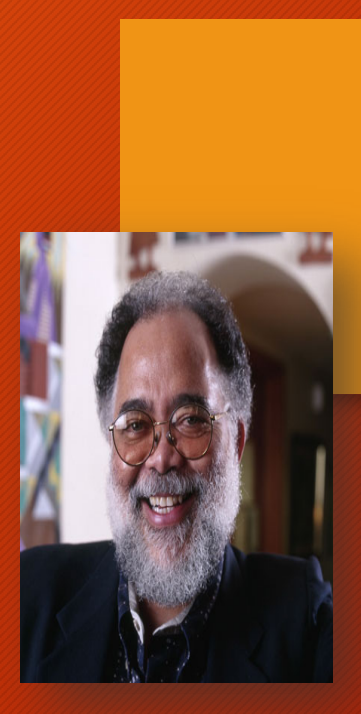

The Routledge companion to the work of John R. Rickford, Routledge, New York (Forthcoming)

Contributors: Robert Bayley Ceil Lucas Joseph Hill Carolyn McCaskill 


\section{In Philly, Sign Language Has Its Own Accent}

Researchers uncover a distinct regional distinction in American Sign Language, and seek to preserve it.

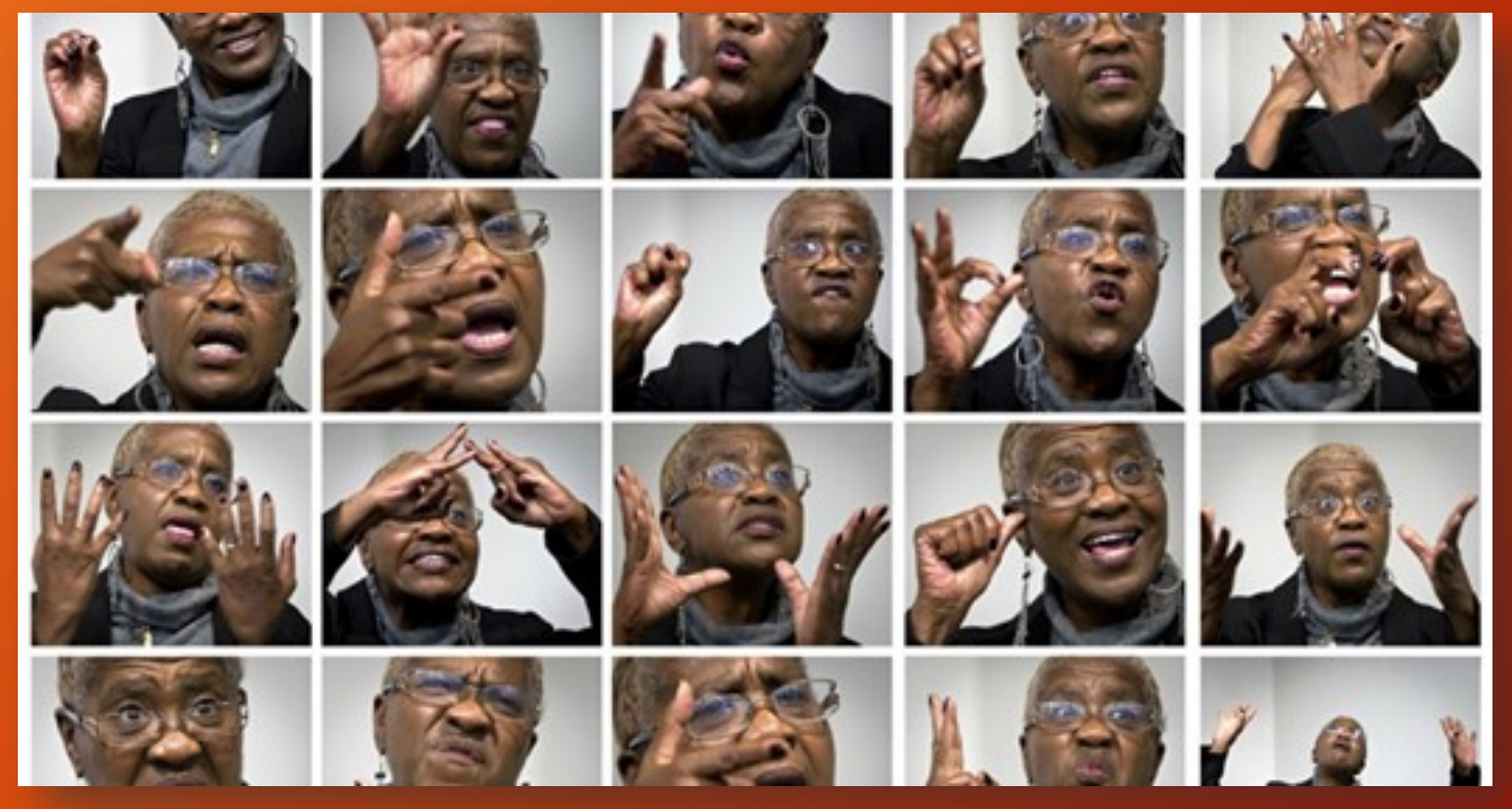

Dec 11, 2016 -The Atlantic.com 


\section{Washington Post \& Atlanta Black Star}

"Sign language that African Americans use is different from that of whites" Sept 17, 2012

"Black American Sign Language is distant from its mainstream" Sept 18, 2012

“Race Matters In Deaf Community" Sept 19, 2012

“There's a Black Sign Language?” The Root Sept 18, 2012

"ASL and Black ASL: Yes, There's a Difference" Feb 25, 2014

"Signs of segregation: The singular challenge" Feb 6, 2015

"The Hidden Treasure of Black Signs: How Segregation Led to the Unique Dialect of Deaf African-Americans" Dec 2,2017 


\section{TALKING BLACK in
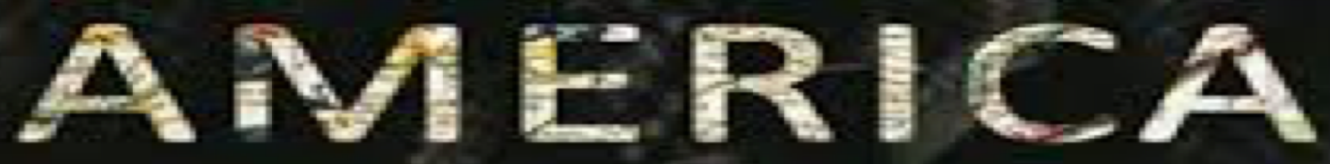

Documentary

- North Carolina State University Language and Life Project. Https: / / languageandlife.org/

Interviews:

- June 2018

- September 2018

Slated for PBS 2019 


\section{BLACK DEAF FAMILIES}

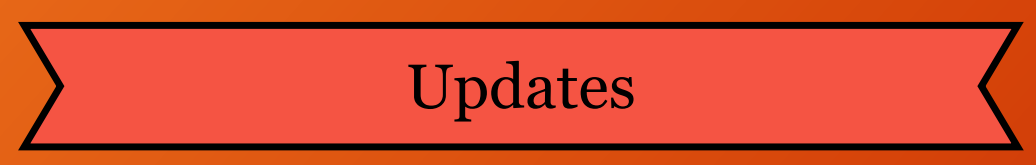

Spinoff

9 individuals from several generations of Black Deaf families

Goals

Plans for the project

Research findings

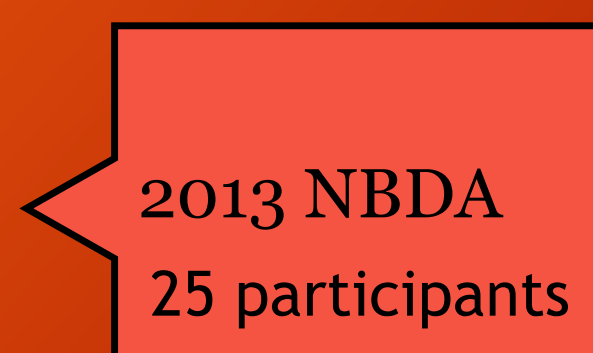

Research assistant 


\section{Acknowledgments}

The research reported here was funded by the Spencer Foundation and the National Science Foundation, whose support is gratefully acknowledged.

Special thanks to the members of the African American Deaf community who generously shared with us the richness of their experience and language. 
